\title{
A extensão universitária na engenharia: aulas de educação ambiental para crianças em situação de vulnerabilidade social
}

\author{
Leandro Bordin ${ }^{1}$, Rodrigo Dal Bosco Fontana ${ }^{2}$, Claudinéia Vieira Raimundi², Thalyta da Silva Vieira²,
}

Mariana Possa ${ }^{2}$

\begin{abstract}
Resumo: O artigo apresenta o projeto de extensão "Educação Ambiental: conscientização para a construção de futuros" desenvolvido por professores e estudantes de Engenharia Ambiental e Sanitária junto ao Programa Social "Viver Ações Sociais" no município de Chapecó-SC. O Programa Viver é um espaço de educação não-formal de crianças e adolescentes em idade escolar entre 6 e 15 anos, nos diferentes aspectos que contemplam uma formação integral, cidadã e crítica. As atividades educativas no âmbito da educação ambiental foram desenvolvidas junto a turmas de crianças com idade entre 6 e 10 anos, levando uma transliteração dos eixos de formação do curso de Engenharia Ambiental e Sanitária da UFFS campus Chapecó - saneamento, recursos hídricos, energias renováveis e gestão ambiental. As oficinas tiveram caráter formativo com práticas diversas como brincadeiras, representações pictóricas, trabalhos em equipe de exploração e afins e tiveram como objetivo a promoção da conscientização ambiental, a ampliação dos conhecimentos e o desenvolvimento de um pensamento crítico acerca dos temas propostos. Durante o período de realização das atividades conseguimos uma satisfatória participação e envolvimento das crianças e através das atividades avaliativas percebemos que, de fato, conseguiram compreender o objetivo do projeto, fixar os principais conceitos trabalhados, e repensar ações - individuais e coletivas - na relação com o meio ambiente.
\end{abstract}

Palavras-chave: Consciência ambiental; Oficinas socioambientais; Formação cidadã

\section{University extension in engineering: environmental education classes for socially vulnerable children}

Abstract: In this paper we present the communitarian project "Environmental Education" carried out by environmental engineering professors and students together with social local action of "Viver Ações Sociais" in Chapeco, Santa Catarina, Brazil. The social action of the "Programa Viver" performs non-formal learning with $6^{\text {th }}$ to $15^{\text {th }}$ aged students in multiple aspects within a perspective of critical and citizenship education. The activities performed by the organizers (students and professors) were carried out with children from 6 to 10 years old, considering the four different branches in the Environmental Engineering of UFFS campus Chapeco - sanitation, water resources, renewable energy and environmental management. The appointments were realized with different practices such as pictorial representations, work team aiming at environmental awareness, knowledge amplification and critical thinking on the proposed subjects. During the period of performance of the activities we achieved a satisfactory participation and involvement of the children, and through the evaluative activities we realized that, in fact, they understood the objective of the project, fixing the main concepts worked on, and rethinking actions - individual and collective - in relation to the environment.

Keywords: Environmental Awareness; Socio-Environmental Workshop; Citizenship Education
Originais recebidos em

26 de março de 2020

Aceito para publicação em

06 de junho de 2020

1

Universidade Federal da Fronteira Sul

- UFFS - campus Chapecó/SC

lbordin@uffs.edu.br

(autor para correspondência)

2

Universidade Federal da Fronteira Sul - UFFS - campus Chapecó/SC 


\section{Introdução - a problemática ambiental}

Os problemas ambientais gerados pelo desenvolvimento tecnológico, econômico e social nunca estiveram tão evidentes. Do ponto de vista da preservação dos recursos naturais ou mesmo da manutenção da vida humana em comunidade, é premente a promoção de uma cultura de educação para o meio ambiente, focada no aspecto do bom aproveitamento de recursos, bem como na boa interação ser humano/meio ambiente, adotando como premissa ações em coletividade.

Autores como Leff (2002), Veiga (2006), Sachs (2007) e Watson et al. (2016) destacam em seus trabalhos que o desenvolvimento econômico não representa mais uma opção aberta, com possibilidades amplas e infinitas para o mundo. A aceitação da ideia de desenvolvimento sustentável, neste contexto, indica que é necessário considerar um limite (superior) para o progresso material. Desta forma, é uma questão de nossa época a discussão e solução das questões do desenvolvimento em relação ao meio ambiente: não é possível um desenvolvimento econômico ilimitado ou isolado dos demais atores sociais do planeta, dada a quantidade de transformações pelas quais este passou nos últimos anos e a escassez de recursos naturais/combustíveis para tal.

Nesse contexto é importante destacar quatro aspectos interconexos (Leff, 2002, Veiga, 2006, Sachs, 2007, Watson et al., 2016):

a) Em primeiro lugar, como vida coletiva, estaremos neste e nos próximos séculos, todos sujeitos às mudanças climáticas advindas do aquecimento global, aceitando ou não a tese de que este seja originado por ação antrópica; embora da inexistência de consenso quanto à ação humana no aquecimento global, há consenso relativamente estabelecido de que, até 2050, estas mudanças podem superar em velocidade espantosa aquelas esperadas até a década de 2010.

b) Em segundo lugar, destaca-se o papel da sustentabilidade neste quadro de interação (coletiva) com o meio; há aqui o alerta de que a política dos novos séculos e as ações tomadas (coletivamente) para o desenvolvimento, ou se pautarão pela sustentabilidade (em todos os múltiplos aspectos a ela condicionados: meio ambiente, economia, política e sociedade), ou não haverá sociedade que sobreviva à explosão de consumo/desenvolvimento deste século.

c) O terceiro aspecto fundamental na discussão das temáticas ambientais é a possibilidade de uma reestruturação na matriz energética mundial, com foco nas energias renováveis, abundantes na natureza e com ação entrópica infinitamente menos potentes na climatologia e ambientes globais; destacamos a matriz energética brasileira como uma das mais promissoras e pujantes na substituição da queima de carvão/fissão de urânio por fontes de energias renováveis do tipo eólica, fototérmica, fotovoltaica, geotérmica e hídrica.

d) O quarto e último aspecto, relaciona-se de maneira direta com a utilização da terra e seus múltiplos recursos, e afeta de maneira fundamental a economia brasileira: a produção de alimentos/matérias-primas e sua conexão com o manejo de recursos hídricos; colocando em voga a questão do próprio consumo interno/externo, é preciso produzir profunda reflexão acerca do modelo produtivo atual, o que encaminha a agroecologia como um modo promissor de harmonizar questões de sustentabilidade com a produção de alimentos.

\section{A Educação Ambiental e a Engenharia (Ambiental e Sanitária)}

A problematização e discussão das questões ambientais supramencionadas se revestem de um caráter social, político e econômico de expressiva magnitude e, desta forma, precisam ser discutidos sob a ótica de sua interdisciplinaridade. Sendo assim, compreendemos que, para além da busca de soluções tecnológicas para 
os problemas (socio)ambientais, a Engenharia Ambiental e Sanitária tem papel fundamental, também, no contexto da Educação Ambiental (EA).

A EA pode ser entendida como aquela em que cada cidadão/educando/educador, toma para si a responsabilidade no processo de interação com o meio ambiente e com a coletividade, uma vez que a solução para os problemas ambientais enfrentados desde nosso tempo será efetiva, apenas se executada coletivamente (Lei Federal № 9.795, de 1999, institui a Política Nacional de Educação Ambiental).

A Política Nacional de Educação Ambiental orienta um enfoque interdisciplinar para os processos educativos da área, tendo como destaque os seguintes objetivos:

a) O desenvolvimento de uma compreensão integrada do meio ambiente em suas múltiplas e complexas relações.

b) O estímulo e o fortalecimento de uma consciência crítica sobre a problemática ambiental e social.

c) O incentivo à participação individual e coletiva, permanente e responsável, na preservação do equilíbrio do meio ambiente.

d) O fomento e o fortalecimento da integração com a ciência e a tecnologia.

e) O fortalecimento da cidadania, autodeterminação dos povos e solidariedade como fundamentos para o futuro da humanidade.

Ramos (2001) destaca que a expressão 'educação ambiental', desde o início dos anos 70, ganha espaço não apenas no campo político, mas nos mais diferentes contextos pedagógicos. Neste lócus - cenário educacional - a EA se desenvolve e serve de suporte teórico e (socio)técnico às atividades que se desenvolvem na área. Isso se dá (ou, idealmente deveria) por meio do constante diálogo com as diferentes esferas - sociais, políticas e econômicas, por exemplo - que integram a busca por soluções, individuais e coletivas, que minimizem os impactos causados pela ação antrópica.

A necessidade de envolver a sociedade civil por meio da conscientização - educação - ambiental é discurso recorrente em trabalhos que versam sobre questões ambientais. Destacamos, neste ponto, os trabalhos de Ramos (2001), Alves (2001), Medeiros et al. (2011), França e Guimarães (2014), Bianchini et al. (2015), Silva et al. (2015), Hansen (2018) e Moitinho (2017) que, por meio de discussões teóricas e de intervenções práticas, em diferentes tempos e espaços, destacam o papel da EA na formação de cidadãos conscientes das múltiplas facetas que contemplam a vida em sociedade.

Alves (2001) discute a estreita relação entre educação para a cidadania e EA. Para o autor, a relação dos cidadãos com a cidade (sociedade) e seus múltiplos problemas - com ênfase aqui para as questões ambientais - passa por algumas fases (Quadro 1) que são impulsionadas, em grande medida, por processos educativos formais ou não-formais.

No alinhamento com os trabalhos supracitados, entendemos que a discussão e entendimento das implicações sociais, políticas, econômicas e ambientais do desenvolvimento tecnológico - educação para a cidadania pode ser feita, nesse caso, pela via da EA. Isso tanto para os estudantes formadores, que precisam compreender interdisciplinarmente os temas de discussão, como para as crianças em formação.

Neste ponto cabe ressaltar a importância da EA no âmbito da educação superior e na sua especificidade para o campo das Engenharias. O Decreto Federal n 4.281, de 25 de junho de 2002 - elaborado e publicado com o objetivo de regulamentar a Lei Federal n 9.795, de 27 de abril de 1999 - torna obrigatória a inclusão da EA em todos os níveis e modalidades de ensino. Tal direcionamento indica que as ações mitigatórias para os problemas ambientais é responsabilidade de todas as profissões e de todos os cidadãos. Também, passa a 
orientar a formação e a atuação dos profissionais de Engenharia numa ótica de interação e integração entre aspectos técnicos e ambientais.

Quadro 1. Fases da educação para cidadania e sua relação com a educação ambiental.

\begin{tabular}{|c|c|}
\hline $\begin{array}{l}\text { (1) } \\
\text { Sensibilização/Tomada de } \\
\text { consciência }\end{array}$ & $\begin{array}{l}\text { O processo de tomada de consciência pode ser fruto de uma capacidade } \\
\text { crítica e avaliativa própria ou ser fruto de ações de sensibilização, integradas } \\
\text { ou não, em experiências de caráter educativo formal; essa fase constitui o } \\
\text { despertar para a ação. }\end{array}$ \\
\hline $\begin{array}{c}\text { (2) } \\
\text { Conhecimento/Apropriação }\end{array}$ & $\begin{array}{l}\text { Uma vez recebida a informação/conhecimento que sirva de substrato para } \\
\text { uma tomada de posição, minimamente fundamentada, o cidadão começa } \\
\text { a assumir o problema como seu. }\end{array}$ \\
\hline $\begin{array}{l}\text { (3) } \\
\text { Reflexão/Questionamento/ } \\
\text { Problematização }\end{array}$ & $\begin{array}{l}\text { O conhecimento da cidade e dos seus múltiplos problemas passa a ser } \\
\text { merecedor de uma ponderação; começam a surgir questões; outros } \\
\text { problemas começam a ser identificados. }\end{array}$ \\
\hline $\begin{array}{l}\text { (4) } \\
\text { Posicionamento/Verbalização } \\
\text { e audição dos outros }\end{array}$ & $\begin{array}{l}\text { A fundamentação obtida permite a tomada de posição; esta deve ser } \\
\text { expressa (comunicada) no âmbito da - de uma - coletividade; a } \\
\text { representação individual é importante, mas o processo mais significativo é } \\
\text { o de partilha, de construção coletiva. }\end{array}$ \\
\hline $\begin{array}{l}\text { (5) } \\
\text { Participação democrática e } \\
\text { Intervenção cívica }\end{array}$ & $\begin{array}{l}\text { O cidadão age conscientemente no sentido da intervenção/ação; o cidadão } \\
\text { se sente apropriado da questão/problema - ambiental, por exemplo - e } \\
\text { pela via da participação democrática é 'chamado' a se envolver nos } \\
\text { processos de decisão. }\end{array}$ \\
\hline
\end{tabular}

Fonte: Alves (2001)

A respeito da EA para crianças das séries iniciais, Medeiros et al. (2011), Bianchini et al. (2015) e Hansen (2018) destacam a importância de o processo de ensino-aprendizagem ser construído por meio das vivências dos estudantes e dos fenômenos que ocorrem à sua volta, buscando apoiá-los com o auxílio dos conceitos científicos pertinentes. Além disso, orientam que as atividades teóricas partam de uma abordagem lúdica, a fim de despertar o interesse, e evoluam para atividades práticas, com o intuito de provocar o posicionamento crítico e estimular possíveis intervenções/ações.

Todos os trabalhos aqui referenciados, em especial o desenvolvido por França e Guimarães (2014), destacam que as ações de EA promovem mudanças de comportamento e despertam nos estudantes o interesse de encontrar soluções para as problemáticas ambientais. Isso pode ser percebido de diferentes formas, que vão desde a capacidade de disseminar informações sobre tais temas, até a mudança de práticas individuais e coletivas frente aos problemas do entorno. As autoras destacam também que as ações de EA precisam ser constantes no âmbito da escola - a EA caracterizada como eixo transversal na/da formação - e que avanços significativos ainda precisam ser feitos no que concerne o envolvimento dos pais, da comunidade e do poder público, em ações e planos voltados à preservação do meio ambiente, despertando, dessa forma, a conscientização para a ação e a busca de soluções concretas para os problemas ambientais. 


\section{Aspectos metodológicos}

O lócus de intervenção/interação do projeto de extensão em questão foi o Programa Social "Viver Ações Sociais" localizado no município de Chapecó/SC. Criado no ano de 1993, é uma entidade sem fins lucrativos, que atende diariamente 150 crianças e adolescentes em situação de vulnerabilidade social, através de atividades em contraturno escolar, oferecendo um espaço de convivência saudável e educativa. Convém destacar que o Programa Viver atua com ações complementares como Grupo de Mulheres e Mães e, no período noturno, em parceria com outras instituições, oferta aulas de ensino Fundamental, Médio e Técnico para jovens e adultos.

Seu propósito, fundamentado na missão de promover o acesso aos direitos sociais do indivíduo, contempla a participação de crianças e adolescentes em atividades socioeducativas, esportivas, culturais e recreativas, além de oferecer acompanhamento psicossocial por assistente social e psicóloga. Nesse contexto, o Programa Viver se constitui como um espaço de educação não-formal, na medida em que o desenvolvimento das atividades/oficinas - extraescolares - têm caráter voluntário, e visam o desenvolvimento humano e social num contexto específico - comunidade - de atuação (Simsom et al., 2001).

O ingresso ao Programa Viver pode ser por procura espontânea, por busca ativa através dos profissionais da entidade, por encaminhamento da rede socioassistencial, e por encaminhamento de outras políticas públicas e para os jovens que, em entrevista social, deve preencher os seguintes critérios:

a) Possuir idade de 6 a 15 anos.

b) Estar estudando na rede de ensino formal.

c) Se encontrar em situação de vulnerabilidade social ou em situação de risco.

d) Preferencialmente pertencer a região de abrangência do Centro de Referência de Assistência Social (CRAS) da região Sul do município de Chapecó.

Todos esses fatores alicerçam a característica de vulnerabilidade social, que é o 'lugar' de atuação do Programa Viver e do contexto deste artigo. Entende-se aqui que a vulnerabilidade e/ou risco social está presente quando o indivíduo - e seu núcleo familiar - deixa de ter condições de usufruir dos mesmos direitos - e deveres - dos outros cidadãos, devido ao desequilíbrio socioeconômico (Carmo; Guizardi, 2018).

Neste contexto - social - e pela identificação da necessidade de práticas de EA no município de Chapecó/SC, pautada na Política Nacional de Educação Ambiental, verificou-se, junto ao Programa Viver, a oportunidade de interação com a comunidade local por meio das crianças participantes do Programa.

O projeto, originalmente denominado "Educação ambiental: conscientização para a construção de futuros", desenvolvido ao longo dos anos de 2018 e 2019, foi organizado a partir dos quatro eixos formativos constituintes da organização curricular do curso de Engenharia Ambiental e Sanitária da Universidade Federal da Fronteira Sul (UFFS), campus Chapecó: saneamento, recursos hídricos, energias renováveis e gestão ambiental. O projeto foi iniciativa de um coletivo de estudantes, num primeiro momento vinculado ao Centro Acadêmico do curso (CA), contando com o apoio e orientação de professores. As ações desenvolvidas atenderam cerca de 50 crianças inscritas no Programa Viver e, em um segundo momento, o grupo de mães e as colaboradoras do Programa.

As atividades foram desenvolvidas com duas turmas de crianças com idade entre 6 e 10 anos. Os encontros ocorreram semanalmente na sede do Programa, com duração de 45 minutos - cada turma - cuja preparação prévia de atividades era sempre discutida e planejada pelo coletivo de estudantes e professores responsáveis. Como citado anteriormente, os eixos de trabalho ao longo do ano, delimitam a estrutura base do Projeto 
Pedagógico do Curso de Engenharia Ambiental e Sanitária, e os principais objetivos pretendidos são apresentados no Quadro 2.

Quadro 2. Objetivos pretendidos em cada eixo de formação do projeto "Educação Ambiental: conscientização para a ampliação de futuros".

\begin{tabular}{|c|c|c|}
\hline Eixo & Objetivos Gerais & Objetivos específicos \\
\hline Saneamento & $\begin{array}{l}\text { Apresentar aos estudantes } \\
\text { conceitos relacionados ao } \\
\text { saneamento } \\
\text { especialmente no que diz respeito } \\
\text { aos resíduos sólidos, abordando } \\
\text { sua importância para a saúde e } \\
\text { qualidade de vida da população. }\end{array}$ & $\begin{array}{l}\text {-Construir a compreensão sobre saneamento básico de modo } \\
\text { que os estudantes possam identificar a importância do tema no } \\
\text { seu cotidiano, relacionando, principalmente, com a realidade do } \\
\text { bairro (existência de coleta seletiva, de tratamento de esgoto e } \\
\text { afins, por exemplo). } \\
\text {-Despertar nos participantes a consciência e preocupação acerca } \\
\text { dos resíduos gerados, demonstrar como e onde devem } \\
\text { depositados e tratados e promover orientações acerca da(s) mais } \\
\text { adequada(s) forma(s) para descarte e separação dos resíduos } \\
\text { sólidos. } \\
\text {-Provocar a percepção sobre os materiais que podem ser } \\
\text { reaproveitados, diminuindo a quantidade de resíduos que são } \\
\text { descartados diariamente. }\end{array}$ \\
\hline $\begin{array}{l}\text { Recursos } \\
\text { Hídricos }\end{array}$ & $\begin{array}{l}\text { Apresentar a importância dos } \\
\text { recursos hídricos com enfoque no } \\
\text { ciclo hidrológico natural, na } \\
\text { qualidade da água, na drenagem } \\
\text { urbana e na utilização adequada } \\
\text { da água da chuva. }\end{array}$ & $\begin{array}{l}\text {-Introduzir o conceito de recursos hídricos do ponto de vista de } \\
\text { sua importância e adequado manejo. } \\
\text {-Abordar os diferentes aspectos do componente água, desde o } \\
\text { ciclo hidrológico até o seu tratamento adequado, enfocando } \\
\text { temas como drenagem e reuso. } \\
\text {-Estimular a construção de um pensamento crítico sobre a água } \\
\text { como recurso em movimento em que se questionem os } \\
\text { diferentes aspectos de nossa relação com seu gerenciamento } \\
\text { desde um ponto de vista individual até coletivo. }\end{array}$ \\
\hline $\begin{array}{l}\text { Energias } \\
\text { renováveis }\end{array}$ & $\begin{array}{l}\text { Apresentar conceitos básicos } \\
\text { sobre energias, abordando as } \\
\text { principais fontes de energias } \\
\text { renováveis sob o ponto de vista da } \\
\text { sustentabilidade }\end{array}$ & $\begin{array}{l}\text {-Relacionar os principais procedimentos de produção de energia } \\
\text { com suas respectivas fontes, adentrando aos conceitos de } \\
\text { energias renováveis e não renováveis; } \\
\text {-Apresentar a importância de fontes alternativas de energias; } \\
\text {-Conhecer as principais características das energias hídrica, solar } \\
\text { e eólica. }\end{array}$ \\
\hline $\begin{array}{c}\text { Gestão } \\
\text { ambiental }\end{array}$ & $\begin{array}{l}\text { Apresentar conceitos básicos } \\
\text { relacionados a gestão ambiental, } \\
\text { abordando sua importância para } \\
\text { a construção de uma sociedade } \\
\text { sustentável, a partir da relação } \\
\text { causa/consequência das } \\
\text { principais atividades promotoras } \\
\text { de degradação ambiental. }\end{array}$ & $\begin{array}{l}\text { Construir o conceito de gestão ambiental e como se dá a sua } \\
\text { prática. } \\
\text {-Identificar principais benefícios da prática de gestão ambiental. } \\
\text {-Conhecer as principais ações antrópicas deflagradoras de } \\
\text { impactos ambientais. } \\
\text {-Identificar as consequências dos impactos ambientais } \\
\text { provenientes das ações antrópicas; } \\
\text {-Conhecer princípios básicos de agroecologia e práticas de } \\
\text { consumo consciente. }\end{array}$ \\
\hline
\end{tabular}

Fonte: Dos autores. 
De modo geral, os 35 encontros contemplaram a introdução/construção dos temas, debates e interação com os participantes, atividades de fixação dos principais conceitos e, por fim, processos de avaliação ao término de cada eixo. Uma vez que o trabalho foi realizado com crianças, as atividades, seguindo as orientações de Medeiros et al. (2011) e Bianchini et al. (2015), partiam via de regra de uma abordagem lúdica. Nesse sentido, foram utilizadas práticas diversas como brincadeiras, representações pictóricas, trabalhos em equipe de exploração e afins, tendo sempre como objetivo a promoção da conscientização ambiental, a ampliação dos conhecimentos e o desenvolvimento de um pensamento crítico acerca dos temas propostos - fases 1, 2 e 3 caracterizadas por Alves (2001) e descritas no Quadro 1.

\section{Percurso formativo: os desafios de ensinar e aprender}

Traçados os objetivos e desenhadas as principais atividades para cada eixo, foi dado início às atividades formativas propriamente ditas. Nossos esforços estiveram concentrados no desenvolvimento de linguagens e dinâmicas condizentes com a idade escolar das crianças envolvidas. Isso requereu muito estudo e preparação por partes dos estudantes e professores formadores, visto que não tínhamos como prática cotidiana o trabalho com crianças. Para além do estudo da temática, o convívio com os estudantes, a avaliação dos acertos e erros, principalmente das primeiras aulas, nos deram o suporte necessário para desenvolvimento do trabalho.

Nesse sentido, os encontros começavam com um diálogo sobre o tema gerador, evoluindo, por exemplo, para a apresentação de um audiovisual - preferencialmente pequenos filmes de animação ${ }^{1}$ - ou uma dinâmica/brincadeira de caráter educativo com foco no tema em discussão, e até mesmo a realização de pequenas peças teatrais.

Na sequência apresentamos os registros das principais atividades.

\section{Eixo 1: Saneamento}

Na primeira atividade sobre o tema Saneamento foi construída a base para as demais aulas. Por meio da fixação de cartazes na parede, foram destacados os principais ramos do saneamento: abastecimento de água, tratamento de esgoto, coleta e tratamento de resíduos sólidos, controle de pragas urbanas e drenagem urbana. O tema foi problematizado por meio de imagens que, no decorrer das discussões, foram sendo fixadas no local correspondente a cada ramo destacado. O movimento de 'acerto' e 'erro' foi explorado didaticamente para a construção dos principais conceitos que seriam trabalhados ao longo dos encontros subsequentes.

Após essa problematização mais ampla sobre o tema, e com o intuito de tornar as discussões de mais fácil entendimento, selecionamos para aprofundamento os seguintes subtemas: (a) saneamento e saúde pública e (b) resíduos sólidos e reciclagem.

No primeiro subtema, buscamos conscientizar que a falta de saneamento básico adequado afeta diretamente a saúde da população. Introduzimos o conteúdo com uma projeção de lâminas em sala de aula, onde foram mostradas algumas das principais doenças e sua principal causa, relacionada com a falta de saneamento. Para fixação dos novos conceitos abordados, ajudamos as crianças na elaboração de uma cartilha informativa. Ao mesmo tempo que elas precisavam lembrar os conceitos para confeccioná-la, ela serviu para que as crianças levassem os conceitos para suas casas, ajudando a conscientizar também a família sobre a importância do saneamento no âmbito da saúde pública.

O subtema sobre resíduos sólidos e reciclagem foi introduzido por meio de um vídeo sobre os tipos de resíduos e a sua correta destinação. Após o entendimento dos conceitos, realizamos uma atividade em que a proposta foi mostrar todo o caminho dos resíduos produzidos no cotidiano de nossas casas, a fim de 
conscientizar de que a nossa responsabilidade não acaba quando colocamos o lixo na lixeira. Nesse ponto aproveitamos muito da(s) experiências(s) das crianças em suas casas e, também, no ambiente do Programa Viver. Numa das tardes realizamos a 'limpeza' no pátio da escola, recolhendo resíduos que deveriam ser destinados para a coleta seletiva. A partir dessa experiência, as crianças ficaram responsáveis por conscientizar as demais turmas do Programa sobre a correta separação dos resíduos no ambiente escolar. Ainda, no eixo de saneamento, realizamos uma oficina de confecção de brinquedos com materiais recicláveis (Figura 1).

Por fim, realizamos uma atividade avaliativa - palavras-cruzadas - para termos um parâmetro do que foi apreendido ao longo dos encontros.

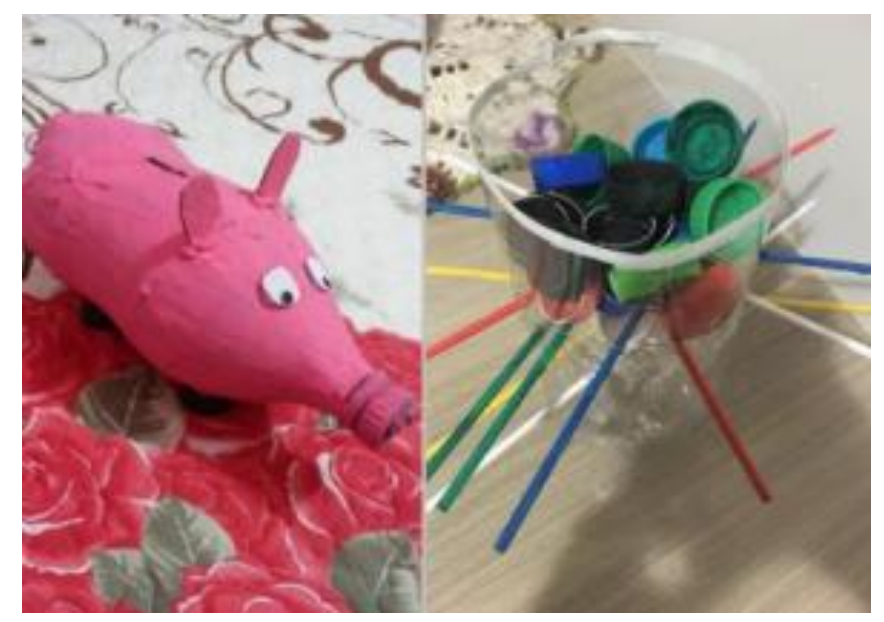

Figura 1. Atividade sobre resíduos sólidos e reciclagem.

Fonte: dos autores.

\section{Eixo 2: Recursos Hídricos}

Nos encontros sobre o eixo Recursos Hídricos foram abordados os seguintes subtemas: (a) ciclo hidrológico, (b) drenagem urbana e utilização da água da chuva, e (c) qualidade da água. A discussão inicial foi sobre a disponibilidade de água doce em nosso planeta, mostrando que apenas uma pequena quantidade, 2,5\%, de água doce, está disponível para o consumo humano. Com isso, demos destaque para a importância da preservação e da qualidade da água.

Quando trabalhamos o subtema sobre ciclo hidrológico, construímos coletivamente um cartaz mostrando cada uma de suas etapas. Na sequência, as crianças foram divididas em duplas, e foi realizado um sorteio para a elaboração de desenho(s) de uma das etapas do ciclo. Então, cada dupla explicou seu desenho para toda turma, de maneira que conseguimos avaliar se os conceitos/termos do ciclo hidrológico foram compreendidos e elaborados.

Para o subtema de drenagem urbana e utilização da água da chuva, foi realizada uma breve introdução em sala de aula sobre o que é drenagem urbana e qual sua importância e, posteriormente, foi realizada uma brincadeira em que algumas crianças representavam a água da chuva, e outras os bueiros e bocas de lobo. A função dessas últimas era 'capturar' a água evitando alagamentos. A respeito da captação e utilização da água da chuva, novamente, aproveitamos a experiência das casas das crianças para problematizar sistemas simples de captação.

No último tema, sobre qualidade da água, foi demonstrada a importância da mata ciliar na absorção da água pela terra, relacionando os mesmos com a qualidade da água. A atividade foi realizada com o auxílio de três 
garrafas pets. a primeira com vegetação, a segunda com um pouco de serapilheira e a terceira sem nenhuma vegetação, e foi dada ênfase para a visualização das diferenças entre absorção e escoamento/arrasto. Neste ponto também fizemos uma experiência com sulfato de alumínio para a limpeza da água (Figura 2). O contexto aqui estava relacionado com as estações de tratamento de água e as redes de abastecimento, mas o exemplo e o acompanhamento da experiência ao longo de alguns dias movimentaram o interesse das crianças.

Para finalizar as atividades do eixo, fizemos, como atividade avaliativa, um jogo de caça-palavras e um exercício de completar lacunas (Figura 3) elencando os principais conceitos abordados sobre recursos hídricos.

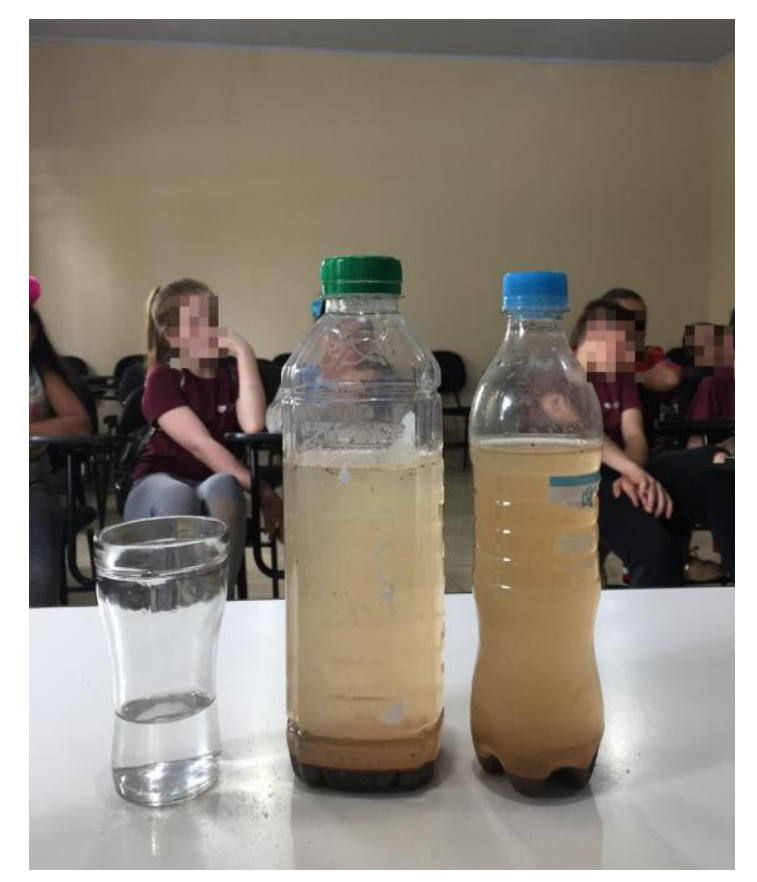

Figura 2. Experiência com sulfato de alumínio para tratamento de água.

Fonte: Dos autores.

Figura 3. Exemplo de atividade avaliativa - completar lacunas - sobre ciclo hidrológico.

Fonte: Dos autores.

Atividade avaliativa

Completar os espaços em branco com as etapas do ciclo hidrológico

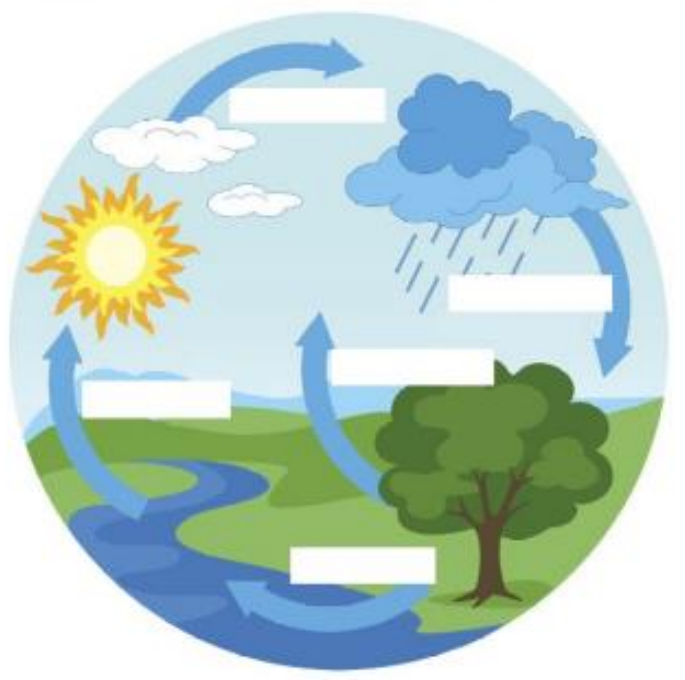




\section{Eixo 3: Energias Renováveis}

O eixo das energias renováveis foi problematizado e discutido com o auxílio principal de maquetes (Figura 4). Fazendo o caminho inverso da energia disponível no cotidiano, foi possível traçar um entendimento da(s) fonte(s) geradora(s) e dos seus impactos no meio ambiente. Por meio da conscientização acerca da escassez e finitude de recursos energéticos, as discussões tiveram como foco as energias (a) hídrica, (b) solar e (c) eólica.

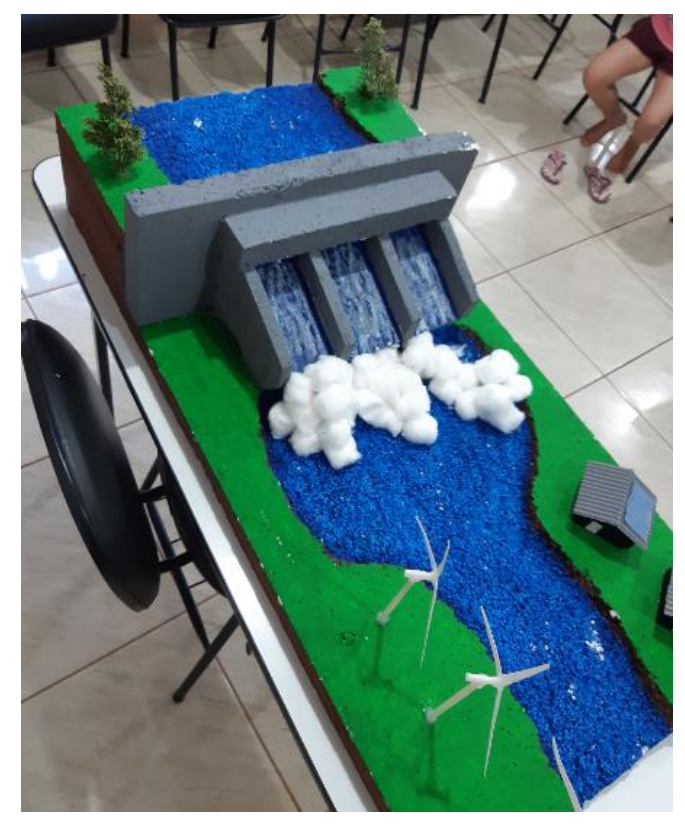

Figura 4. Maquete para problematização e discussão do tema energias renováveis.

Fonte: Dos autores.

As discussões estiveram centradas na geração da energia proveniente da fonte natural, até a sua conversão e distribuição em forma de energia elétrica ou motora. Também, foram exibidos vídeos e animações - de canais da internet que versam sobre o assunto -, sobre como se pode produzir energia através da natureza, e como é possível reduzir as emissões de gases de efeito estufa, por exemplo, através da utilização das referidas energias. Além disso, foram feitas ilustrações e realizadas brincadeiras como caça-palavras e telefone-sem-fio, para fixação dos principais conceitos.

Convém destacar que este eixo, em específico, foi um elemento fomentador de discussões sobre o conceito de desenvolvimento sustentável. De forma simples e prática, buscamos construir o entendimento de que a minimização de impactos ambientais, materializada por meio de ações individuais e coletivas no cotidiano, é capaz de encaminhar um desenvolvimento comprometido com o futuro do planeta e de todas as espécies.

\section{Eixo 4: Gestão Ambiental}

Para as construções em torno do eixo de gestão ambiental, selecionamos dois subtemas para discussão: (a) conscientização ambiental - ações antrópicas e suas influências - e (b) consumo consciente e redução de desperdícios.

Na dinâmica sobre conscientização ambiental, buscamos fazer com que as crianças, através de uma atividade de completar frases, refletissem a respeito das ações que devem ser tomadas no cuidado com o meio ambiente, principalmente no âmbito coletivo, ou seja, da gestão (pública). Mais uma vez foram usados exemplos do cotidiano do bairro e da cidade, para uma maior compreensão do tema. Assim, a (in)eficiência da coleta seletiva no bairro - periférico - em relação a outros bairros da cidade, e a implantação do Programa Lixo Zero, realizada pela prefeitura da cidade, foram temas disparadores das discussões. 
Como atividade resultante das discussões sobre a importância de áreas verdes - praças, parques e afins realizamos o plantio de mudas de árvores na sede do Programa Viver (Figura 5). Na ocasião discutimos sobre a importância das árvores no meio ambiente - na regulação da temperatura e na melhora da qualidade do ar, por exemplo. Cada turma ficou responsável pelo cuidado e acompanhamento das mudas plantadas.

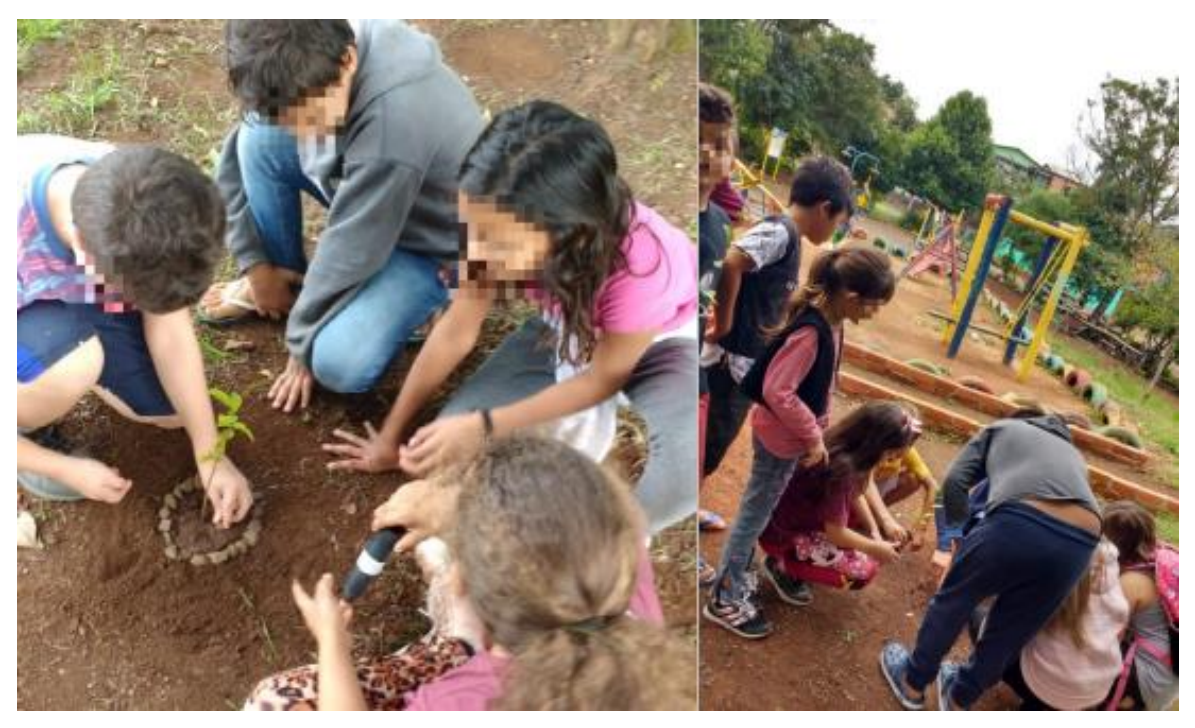

Figura 5. Plantação de mudas de árvores frutíferas.

Fonte: Dos autores.

Finalmente, para os encontros sobre consumo consciente, apresentamos vídeos que falavam a respeito do tema, seguidos sempre de estímulo/provocações para que as crianças fizessem suas elaborações/construções. Uma vez que a limpeza do pátio escolar - realizada durante o eixo de saneamento - havia resultado em expressiva quantidade de resíduos, aproveitamos, neste momento, para estimular a consciência pela sua não geração. Além disso, falamos sobre formas de minimizar desperdícios, e trouxemos o exemplo de uma miniatura de minhocário/composteira, dando ênfase ao adubo como um (sub)produto do resíduo orgânico gerado.

A exemplo dos demais eixos, foi realizada atividade avaliativa, no final dos encontros sobre gestão ambiental.

\section{Considerações Finais}

Ao objetivarmos a promoção da conscientização ambiental, a ampliação dos conhecimentos e o desenvolvimento de um pensamento crítico acerca da relação ser humano/meio ambiente, finalizamos as atividades do projeto de extensão "Educação Ambiental: conscientização para a construção de futuros" com resultados bastante satisfatórios. Durante o período de realização das atividades, conseguimos uma expressiva participação e envolvimento das crianças e, através das atividades avaliativas, percebemos que, de fato, conseguiram compreender o objetivo do projeto, elaborar os principais conceitos trabalhados e repensar ações - individuais e coletivas - na relação com o meio ambiente.

De forma objetiva isso pode ser percebido pelo número de acertos apresentados em atividades teóricas como palavras-cruzadas e tarefas de completar lacunas e em atividades práticas como a correta separação de resíduos sólidos. No entanto, entendemos que alguns resultados são de um campo mais subjetivo e, portanto, 
difíceis de se mensurar com tais atividades. Destacamos, neste campo, a incorporação de termos técnicos como, por exemplo, 'resíduos sólidos' e 'aterro sanitário' nas falas das crianças durante as aulas.

Também foi comum ouvirmos sobre experiências que acontecem em casa e no seu entorno. Inúmeros foram os exemplos - e contraexemplos - trazidos pelas crianças, e que foram acolhidos e discutidos com a turma. Tais experiências nos levaram a realizar dois encontros com o grupo de mães que periodicamente se reúne na sede do Programa Viver. Nesses encontros foi debatida, principalmente, a adequada separação e destinação de resíduos sólidos. Dessa experiência resultou o interesse do nosso grupo para, em ações futuras de extensão, ampliarmos o escopo de atuação para o bairro como um todo. Nesse sentido, atenderíamos a recomendação dada por França e Guimarães (2014), do envolvimento dos pais e da comunidade, e inclusive do poder público, uma vez que, de forma organizada, o coletivo do bairro poderia buscar soluções para os principais problemas do entorno - fases 4 e 5, caracterizadas no trabalho de Alves (2001), e descritas no Quadro 1.

A avaliação das atividades foi uma prática constante do grupo de extensionistas. Ao longo do percurso fomos tomando ainda mais consciência de que nosso papel não era o de 'ensinar' conteúdos técnicos. Em muitos momentos, tivemos que parar o conteúdo programado para estabelecer com a turma alguns sinais comunicativos simples como, por exemplo, levantar a mão antes de falar. O tema bullying e brigas foi problematizado por meio de vídeos e muita conversa. Importante destacar que o Programa Viver conta com o trabalho de uma equipe multidisciplinar, à qual recorremos algumas vezes, mas muitas situações tiveram que ser resolvidas no cotidiano da sala de aula.

Por fim, destacamos que aprendemos tanto quanto ensinamos, e que esse processo nos tornou profissionais de Engenharia mais sensiveis e comprometidos com o caráter socioambiental da formação e atuação no/do campo da Engenharia Ambiental e Sanitária.

\section{Nota}

1. Exemplos de vídeos/animações:
a) Cuidados com o meio ambiente: https://www.youtube.com/watch?v=pT80h4307F8\&t=73s
b) Resíduos Sólidos: https://www.youtube.com/watch?v=oJsvzfLgKTw
c) Preservação do recurso natural água: $h$ ttps://www.youtube.com/watch?v=cPsHGpXpI-U
d) Energias renováveis: https://www.youtube.com/watch?v=6r0EgxExbEU

\section{Contribuições de cada autor}

Os autores L.B. e R.D.B.F. foram responsáveis pela coordenação e orientação da equipe de extensionistas e pela escrita do presente artigo. Os autores C.V.R., T.S.V. e M.P. contribuíram com a escrita do relato de experiência do projeto em questão e foram as responsáveis pela execução das atividades, e pelo desenvolvimento do material utilizado para as aulas.

\section{Referências}

Alves, F. L. (2001). Educação ambiental e educação para a cidadania. OLAM-Ciência \& Tecnologia, 1(1), $160-175$.

Bianchini, D. C., Fank, J. C., Seben, D., Rodrigues, P., \& Rodrigues, A. C. (2015). Sustentabilidade e Educação Ambiental na Escola Estadual de Ensino Fundamental Waldemar Sampaio Barros. Revista Monografias Ambientais, 14, 188-194. 
Carmo, M. E. D., \& Guizardi, F. L. (2018). O conceito de vulnerabilidade e seus sentidos para as políticas públicas de saúde e assistência social. Cadernos de Saúde Pública, 34(3), e00101417.

França, P. A. R. de, \& Guimarães, M. D. G. V. (2014). A educação ambiental nas Escolas Municipais de Manaus (AM): um estudo de caso a partir da percepção dos discentes. Revista Monografias Ambientais, 13(2), 3128-3138.

Hansen, K. S. (2013). Metodologias de ensino da Educação Ambiental no âmbito da Educação Infantil. Revista Educação Ambiental em Ação, 43, idartigo=1467.

Leff, E. (2002). Agroecologia e saber ambiental. Agroecologia e Desenvolvimento Rural Sustentável, 3(1), 36-51.

Medeiros, A. B. D., Mendonça, M. J. S. L., Sousa, G. L. D., \& Oliveira, I. P. D. (2011). A Importância da educação ambiental na escola nas séries iniciais. Revista Faculdade Montes Belos, 4(1), 1-17.

Moitinho, E. B., Campos, G. M., Machado, I. B., Figueredo, D. M., Mendes, I. M. F., \& Sales, R. M. M. (2017). A educação ambiental como instrumento de sensibilização para reutilização de resíduos sólidos. Revista Verde de Agroecologia e Desenvolvimento Sustentável, 12(5), 874-878.

Ramos, E. C. (2001). Educação ambiental: origem e perspectivas. Educar em Revista, 17(18), 201-218.

Sachs, I. (2007). A revolução energética do século XXI. Estudos Avançados, 21(59), 21-38.

Silva, A., Mesquita, G., \& Souza, M. (2015). Educação ambiental como paradigma para a construção da sustentabilidade. Revista Eletrônica em Gestão, Educação e Tecnologia Ambiental, 19(2), 1133-1140.

Simsom, O. R. M., Park, M. B., \& Fernandes, R. S. (2001). Educação não-formal: Cenários da Criação. Campinas: Unicamp. Veiga, J. E. (2006). Desenvolvimento Sustentável: O desafio do século XXI. Rio de Janeiro: Garamond.

Watson, R., Carraro, C., Canziani, P, Nakicenovic, N., McCarthy, J. J., Goldemberg, J, \& Hisas, L. (2016). The truth about climate change. Watson, R. et al. The Truth About Climate Change. [s. I.]: FEU-US. Recuperado de: https://drive.google.com/file/d/OB9whT-2Ezzu7c0F3S09KVGFQSnM/view

Como citar este artigo:

Bordin, L., Fontana, R. D. B., Raimundi, C. V., Vieira, T. S., \& Possa, M. (2020). A extensão universitária na Engenharia: aulas de educação ambiental para crianças em situação de vulnerabilidade social. Revista Brasileira de Extensão Universitária, 11(2), 153-165. https://periodicos.uffs.edu.br/index.php/RBEU/article/ view/10399/pdf 